\title{
Risk Factors for Progression in Patients with Early-stage Chronic Kidney Disease in the Japanese Population
}

\author{
Takumi Yoshida, Takashi Takei, Satsuki Shirota, Misao Tsukada, Hidekazu Sugiura, \\ Mitsuyo Itabashi, Tetsuya Ogawa, Keiko Uchida, Ken Tsuchiya and Kosaku Nitta
}

\begin{abstract}
Objective Chronic kidney disease (CKD) is an important worldwide health problem. The incidence of endstage renal disease (ESRD) is increasing steadily around the world, however few studies have discussed the risk factors for progression in patients with early-stage CKD. Therefore, we designed a retrospective cohort study of patients with early-stage CKD to identify the risk factors influencing the annualized slope of the estimated glomerular filtration rate (eGFR).

Methods and Patients In this longitudinal cohort study, baseline examination was conducted in 2012 outpatients treated at the Kidney Center, Tokyo Women's Medical University. Follow-up examinations were completed in 485 patients with stage 1 and stage 2 CKD within the study period (2002-2007). The conventional risk factors for CKD progression, such as proteinuria, blood pressure, serum triglyceride, serum HDL, fasting plasma glucose, smoking habit, hypertension or treatment with antihypertensive medication and body mass index, were examined. The annualized eGFR slope was calculated at the start and end of the study period. Multivariate analysis was performed to determine the associations of the eGFR slope with the predisposing risk factors.

Results The mean annualized eGFR slope was $-1.64 \mathrm{~mL} / \mathrm{min} / 1.73 \mathrm{~m}^{2} /$ year. Concerning the relationship between etiology and the GFR decreasing slope, IgA nephropathy was defined as the worst $(-1.80 \mathrm{~mL} / \mathrm{min} /$ year) due to the high ratio of proteinuria. Proteinuria $\left(-2.13 \mathrm{~mL} / \mathrm{min} / 1.73 \mathrm{~m}^{2} /\right.$ year, $\left.\mathrm{p}=0.005\right)$, smoking habit $\left(-2.06 \mathrm{~mL} / \mathrm{min} / 1.73 \mathrm{~m}^{2} /\right.$ year, $\left.\mathrm{p}=0.014\right)$, low serum HDL $\left(-1.95 \mathrm{~mL} / \mathrm{min} / 1.73 \mathrm{~m}^{2} /\right.$ year, $\left.\mathrm{p}=0.035\right)$, and hypertension $\left(-1.73 \mathrm{~mL} / \mathrm{min} / 1.73 \mathrm{~m}^{2} /\right.$ year, $\left.\mathrm{p}=0.045\right)$ were all significantly related to the eGFR slope. The estimated GFR for the highest BMI quartile was significantly higher than that of the eGFR for the lowest BMI.

Conclusion Proteinuria, smoking habit, hypertension and low HDL were clearly related to accelerated disease progression in patients with early-stage CKD. Therefore, aggressive treatment of these risk factors is essential in the early stages of CKD.
\end{abstract}

Key words: chronic kidney disease, GFR, hyperlipidemia, hypertension, proteinuria, smoking

(Inter Med 47: 1859-1864, 2008)

(DOI: 10.2169/internalmedicine.47.1171)

\section{Introduction}

Chronic kidney disease (CKD) is an important worldwide health problem. The incidence of end-stage renal disease (ESRD) is increasing steadily around the world. Imai et al reported that the number of patients with ESRD in Japan has increased steadily over the last three decades, and about $20 \%$ of the Japanese adult population (i.e., approximately 19 million people) is currently estimated to suffer from stage 3 to $5 \mathrm{CKD}$; it has thus became a national issue $(1,2)$. CKD is also a major risk factor for cardiovascular disease and death $(3,4)$. Therefore, aggressive treatment of CKD is more important than was envisioned before.

A number of studies have examined the risk factors, including hypertension, proteinuria, hyperlipidemia, smoking habit, advanced age, male, and obesity, for CKD progression. In addition to the above, metabolic syndrome has also 
Table 1. Clinical Characteristics of Study Population

\begin{tabular}{lcc}
\hline Variables & start of study & end of study \\
\hline Age (years) & $41.5+/-7.0$ & \\
M/F (n) & $202 / 283$ & \\
Height & $163.1+/-0.7$ & \\
Body weight & $59.4+/-12.6$ & \\
Body mass index & $22.9+/-4.1$ & \\
Systolic blood pressure (mm Hg) & $117.7+/-14.1$ & \\
Diastolic blood pressure (mm Hg) & $72.5+/-11.2$ & \\
Serum HDL cholesterol (mg/dL) & $60.7+/-21.3$ & \\
Triglyceride (mg/dL) & $150.2+/-130.0$ & $0.82+/-0.39$ \\
Fasting plasma glucose (mg/dL) & $106.25+/-24.0$ & $78.4+/-14.9$ \\
Serum Cr (mg/dL) & $0.73+/-0.19$ & \\
eGFR (mL/min/1.73 m²) & $86.6+/-15.8$ & \\
Smoking habit (\%) & $24.3 \%$ & \\
\hline
\end{tabular}

been recognized as a significant risk factor in these patients. The objectives in many target population in most of these studies was CKD patients of all stages or subjects who presented themselves for health screening examinations. It is believed that appropriate treatment in the early stage is very important for delaying the progression of CKD. To date, few studies have focused on the early stage of CKD.

To examine these issues and highlight the importance of treating risk factors for progression of CKD even from the early stage in patients with CKD, we designed a retrospective cohort study to identify, by multiple regression analysis, the risk factors influencing the annualized slope of the eGFR in patients with early-stage CKD visiting the outpatient department of the Tokyo Women's Medical University.

\section{Methods}

\section{Study design and population}

Of the 2012 outpatients visiting the Kidney Center at Tokyo Women's Medical University, Japan, who were screened, follow-up examinations could be completed in 485 patients. The annualized eGFR was determined and compared among the patients with various risk factors, including the metabolic syndrome. The patients were diagnosed by renal biopsy. The patients who did not undergo renal biopsy were categorized into the unknown group. Patients with diabetic nephropathy and polycystic kidney disease were excluded, because their body weight is known to be related to the progression of these diseases. The estimated GFR was calculated by the re-expressed simplified MDRD equation modified by Japanese coefficient: GFR $\left(\mathrm{mL} / \mathrm{min} / 1.73 \mathrm{~m}^{2}\right)=$ $175 \times \mathrm{S}^{-\mathrm{Cr}^{-1.154}} \times \mathrm{Age}^{-0.203} \times 0.741 \times(0.742$ if female $)(5)$. Serum creatinine was measured using an enzyme-based method. The rate of change of the eGFR was calculated as the eGFR slope using the following equation:

GFR slope $\left(\mathrm{mL} / \mathrm{min} / 1.73 \mathrm{~m}^{2} / \mathrm{y}\right)=($ GFR in $2007[\mathrm{~mL} / \mathrm{min} /$ $\left.1.73 \mathrm{~m}^{2}\right]$ - GFR in $\left.2002\left[\mathrm{~mL} / \mathrm{min} / 1.73 \mathrm{~m}^{2}\right]\right) / 5$

High age was defined as more than 60 years old (6). Obesity was defined as $\mathrm{BMI} \geq 25 \mathrm{~kg} / \mathrm{m}^{2}$. Blood pressure was measured 3 times with a standard mercury sphygmomanometer with the subject in the sitting position, after she/he had rested for at least 5 minutes; the means of the 3 measurements were used for the analysis. Blood samples were collected from the antecubital vein after the patients had fasted overnight, for determination of the serum creatinine, blood glucose and serum HDL cholesterol. Freshly voided samples were collected for urinalysis, and proteinuria was defined as a $1+$ result on a reagent strip or $0.3 \mathrm{~g}$ protein $/ \mathrm{g}$ creatinine.

Metabolic syndrome was defined according to the modified diagnostic criteria of metabolic syndrome of the National Cholesterol Education Program (NCEP) - Adult Treatment Panel III (ATPIII) (7). Elevated blood pressure was defined as an average systolic/diastolic blood pressure of 130/85 mm Hg or greater and/or current use of antihypertensive medication. Hypertriglyceridemia was defined as a serum triglyceride level of $150 \mathrm{mg} / \mathrm{dL}$ or greater. Low serum HDL cholesterol was defined as a level less than 40 $\mathrm{mg} / \mathrm{dL}$ in men and less than $50 \mathrm{mg} / \mathrm{dL}$ in women. Metabolic syndrome was defined as the presence of 3 or more of the above-mentioned criteria.

\section{Statistical analysis}

All statistical analyses were conducted with the JMP software (version 5.0.1J; SAS Institute, Tokyo). Multiple linear regression analysis using the eGFR slope as the objective variable, adjusted for with the various risk factors serving as 
Table 2. Diagnosis and eGFR Slope

\begin{tabular}{|c|c|c|c|c|c|c|c|c|c|}
\hline & $\begin{array}{c}\mathrm{n} \\
(\%)\end{array}$ & $\begin{array}{l}\text { age } \\
\text { (mean) }\end{array}$ & $\begin{array}{c}\text { basal eGFR } \\
\left(\mathrm{mL} / \mathrm{min} / 1.73 \mathrm{~m}^{2}\right)\end{array}$ & $\begin{array}{l}\text { Proteinuria } \\
\quad(\%)\end{array}$ & $\begin{array}{c}\text { Hypertension } \\
(\%)\end{array}$ & $\begin{array}{l}\text { Low HDL } \\
(\%)\end{array}$ & $\begin{array}{c}\text { ACE/ARB } \\
(\%)\end{array}$ & $\begin{array}{c}\text { Smoking } \\
(\%)\end{array}$ & eGFR slope \\
\hline $\operatorname{Ig} \mathrm{A}-\mathrm{N}$ & $165(34)$ & $32.2+/-11.9$ & 85.5 & 47.8 & 22.4 & 8.5 & 41.2 & 18.8 & $-1.80+/-0.54$ \\
\hline $\mathrm{MC}$ & $92(19)$ & $38.1+/-17.2$ & 90.4 & 19.6 & 19.6 & 12.0 & 29.3 & 34.8 & $-1.34+/-0.39$ \\
\hline SLE & $85(18)$ & $38.8+/-11.7$ & 89.8 & 27.1 & 25.9 & 3.5 & 23.5 & 30.6 & $-1.30+/-0.46$ \\
\hline FSGS & $54(11)$ & $32.2+/-10.9$ & 84.4 & 50.0 & 27.8 & 5.6 & 38.9 & 25.9 & $-1.74+/-0.64$ \\
\hline Unknown & $84(18)$ & $47.5+/-15.9$ & 83.7 & 50.0 & 39.3 & 28.6 & 38.1 & 17.9 & $-2.14+/-0.63$ \\
\hline Total & $480(100)$ & $41.5+/-7.0$ & 86.6 & 39.4 & 26.0 & 11.5 & 35.0 & 24.6 & $-1.64+/-0.48$ \\
\hline
\end{tabular}

Table 3. Multivariate Analysis of the Association of eGFR Decline with Predisposing Factors

\begin{tabular}{|c|c|c|c|c|}
\hline \multirow[t]{2}{*}{ Variables } & \multicolumn{2}{|c|}{ eGFR slope } & \multirow{2}{*}{$\begin{array}{l}\text { Correlation } \\
\text { coefficient }\end{array}$} & \multirow[t]{2}{*}{$\mathrm{p}$ value } \\
\hline & Presence & Absence & & \\
\hline Age $(60 \leq$ vs $<60)$ & $-1.74+/-0.92(75)$ & $-1.77+/-0.85(405)$ & & 0.492 \\
\hline Gender (male vs. female) & $-1.61+/-0.47(202)$ & $-1.72+/-0.48(283)$ & & 0.782 \\
\hline High body mass index $(25 \leq \mathrm{vs}<25)$ & $-2.04+/-0.82(85)$ & $-1.57+/-0.65(203)$ & & 0.167 \\
\hline Metabolic syndrome & $-2.15+/-1.24(76)$ & $-1.59+/-0.96(187)$ & & 0.190 \\
\hline Proteinuria* (vs absence) & $-2.13+/-1.02(189)$ & $-1.55+/-0.88(291)$ & -0.302 & 0.005 \\
\hline Hypertension* (vs absence) & $-1.73+/-0.61(125)$ & $-1.65+/-0.52(355)$ & -0.201 & 0.045 \\
\hline High triglyceride (vs absence) & $-1.68+/-0.53(158)$ & $-1.61+/-0.47(322)$ & & 0.450 \\
\hline Low HDL cholesterol* (vs absence) & $-1.95+/-0.45(38)$ & $-1.53+/-0.43(313)$ & -0.215 & 0.035 \\
\hline $\begin{array}{l}\text { High Fasting plasma glucose (vs } \\
\text { absence) }\end{array}$ & $-1.74+/-0.54(142)$ & $-1.62+/-0.47(265)$ & & 0.241 \\
\hline Smoking habit *(vs absence) & $-2.06+/-0.77(64)$ & $-1.58+/-0.52(196)$ & -0.243 & 0.014 \\
\hline ACEI/ARB therapy & $-1.90+/-0.78(168)$ & $-1.54+/-0.64(312)$ & & 0.392 \\
\hline CCB therapy & $-1.88+/-0.48(113)$ & $-1.53+/-0.48(367)$ & & 0.412 \\
\hline
\end{tabular}

the explanatory variables was performed. These risk factors for explanatory variables were expressed as binary variables, while the BMI was divided into quartiles $(\leq 20,20-25,25-$ $30,30<)$. The unpaired t-test was used to analyze the differences in the values among the quartiles. $p$ values of less than 0.05 were considered to denote significance.

\section{Results}

\section{Clinical characteristics of the study population}

The baseline characteristics of the subjects are listed in Table 1 . The subjects ranged in age from $15 \mathrm{y} / \mathrm{o}$ to $84 \mathrm{y} / \mathrm{o}$. The BMI, systolic blood pressure, diastolic blood pressure, and serum HDL cholesterol were within the normal ranges in all the subjects. However, the serum triglyceride and fasting plasma glucose tended to be high; this could be attributable to the influence of nephrotic syndrome or corticosteroid treatment. The etiology of CKD in the subject population and the ratio of significant risk factors as indicated Table 3 are shown in Table 2. The mean eGFR slope was $-1.64 \mathrm{~mL} /$ $\min / 1.73 \mathrm{~m}^{2} /$ year. IgA nephropathy, minimal-change (MC) nephropathy, systemic lupus erythematosus (SLE), and focal and segmental glomerular sclerosis (FSGS) were the causes of CKD in 34, 19, 18 and $11 \%$, respectively. Unexpectedly, the slope for IgA nephropathy was the steepest $(-1.80 \mathrm{~mL} /$ $\min / 1.73 \mathrm{~m}^{2} /$ year), and those for MC, SLE, and FSGS, and unknown were $-1.34,-1.30$, and $-1.74 \mathrm{~mL} / \mathrm{min} / 1.73 \mathrm{~m}^{2} /$ year, respectively. However, these "worse" etiologies such as IgA nephropathy, FSGS and unknown showed a high ratio of proteinuria.

\section{Multivariate analysis to determine the association of the eGFR slope with the predisposing risk factors}

Table 3 shows that proteinuria $\left(-2.13 \mathrm{~mL} / \mathrm{min} / 1.73 \mathrm{~m}^{2}\right.$ / year, $\mathrm{p}=0.005)$, smoking habit $\left(-2.06 \mathrm{~mL} / \mathrm{min} / 1.73 \mathrm{~m}^{2} /\right.$ year, $\mathrm{p}=0.014)$, low HDL $\left(-1.95 \mathrm{~mL} / \mathrm{min} / 1.73 \mathrm{~m}^{2} /\right.$ year, $\left.\mathrm{p}=0.035\right)$ and hypertension $\left(-1.73 \mathrm{~mL} / \mathrm{min} / 1.73 \mathrm{~m}^{2} /\right.$ year, $\left.\mathrm{p}=0.045\right)$ were significantly related with the eGFR slope. On the other hand, male, high BMI and metabolic syndrome showed no significant relation to the eGFR in this study. Furthermore, treatment with ACE inhibitor and angiotensin receptor blocker (ARB) were not significantly related with the eGFR slope, although these are expected to maintain renal func- 


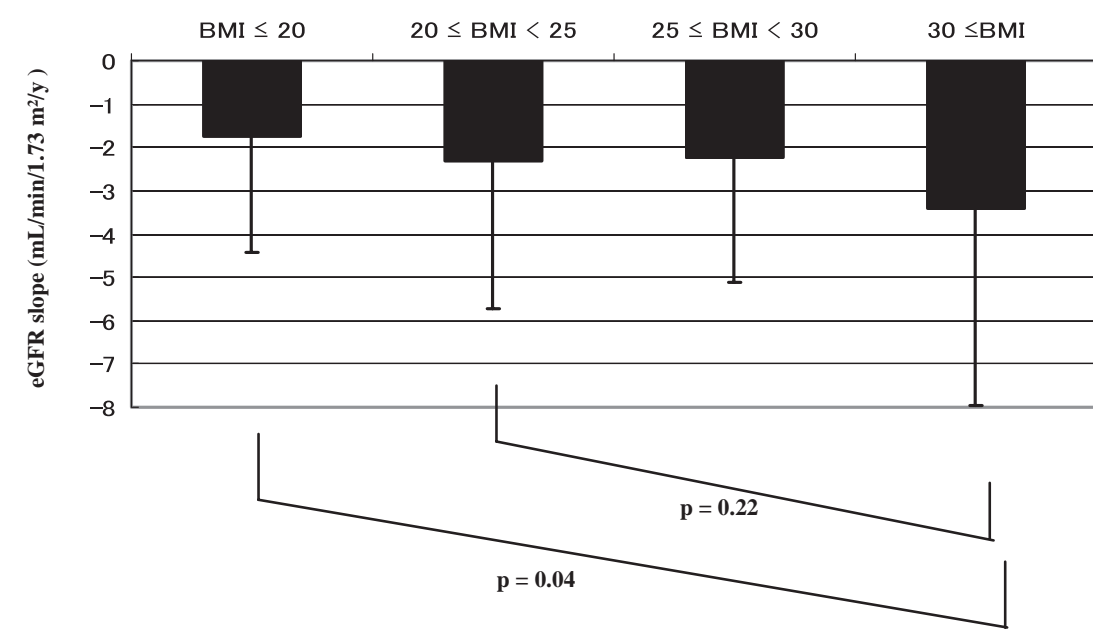

Figure 1. Univariate analysis of the association of eGFR slope and Body Mass Index quartile. Highest BMI quartile was significantly higher than the lowest BMI quartile in eGFR slope, however other pairs between quartile did not show a significant difference. $p$ values of less than 0.05 were considered significant.

tion.

\section{Association of the eGFR slope with the BMI quartile}

The results of multivariate analysis revealed that a high BMI was not associated with a steeper eGFR as compared to normal BMI. Then, the associations of BMI values in different quartiles to the annualized eGFR slope were analyzed by student's t-test. The estimated GFR for BMI in the highest quartile $\left(-3.40 \mathrm{~mL} / \mathrm{min} / 1.73 \mathrm{~m}^{2} /\right.$ year $)$ was significantly higher than the eGFR for the lowest BMI $(-1.75 \mathrm{~mL} / \mathrm{min} /$ $1.73 \mathrm{~m}^{2} /$ year), although the eGFR for a normal BMI quartile was not significant as compared with that for BMI in the high quartile (Fig. 1).

\section{Discussion}

In our retrospective study of a cohort of patients with early-stage CKD, the mean eGFR slope was $-1.6 \mathrm{~mL} / \mathrm{min} /$ year, and $\operatorname{IgA}$ nephropathy was unexpectedly the worst etiology of the CKD. However these worse etiologies such as IgA nephropathy, FSGS and unknown etiology showed high ratio of proteinuria, and low basal eGFR. Therefore the difference of eGFR slope between etiologies could be influenced by the ratio of proteinuria and basal eGFR. A positive and significant association of the slope was seen with the classical risk factors, namely, proteinuria, smoking habit, low HDL and hypertension. These data are consistent with previous reports (8). Of all the risk factors, proteinuria was found to be the most significant. Ruggenenti et al reported that a urinary protein excretion level of more than $1 \mathrm{~g} /$ day is an important risk factor for progression of renal function in patients with chronic glomerulonephritis (9). In our previous study, we reported proteinuria of more than $1 \mathrm{~g} /$ day as an important risk factor in CKD patients (8). In this study, an even smaller amount of proteinuria $(0.3 \mathrm{~g} / \mathrm{g}$ creatinine $)$ was found to be a risk factor in the CKD patients. In our previ- ous report, we found, however, that proteinuria was no longer a significant risk factor in patients with stage 4 or stage $5 \mathrm{CKD}$. Aggressive treatment to decrease proteinuria at an early stage of CKD is, therefore, of utmost importance. Furthermore, our study results also confirmed the importance of screening by urinalysis (10).

Smoking was also found to be a major risk factor for CKD progression in this study. There are numerous reports suggesting that smoking accelerates the progression of kidney disease. Keller et al reported that the odds ratio for albumin excretion in diabetic patients was surprisingly 26.3 for current smoking, but 1.32 and 3.42, respectively, for nighttime systolic blood pressure and $1 \%$ increment in glycosylated HbA1 (11). Orth et al reported that in patients with IgA nephropathy or polycystic kidney disease, a significant dose-dependent increase of the risk of progression to ESRD was found, with an odds ratio of 5.8 in current smokers (12). They also reported that the GFR reduction rate in smokers was $5.3 \mathrm{~mL} / \mathrm{min} /$ year, while that in nonsmokers was $2.5 \mathrm{~mL} / \mathrm{min} /$ year; that is, smoking was associated with a doubling of the eGFR reduction rate $(13,14)$. Therefore, nephrologists have the onus of educating patients on the importance and necessity of smoking cessation.

Low serum HDL was also found to be one of the significant risk factors for accelerated deterioration of renal function, whereas high serum triglyceride was not. The MDRD study also reported that a low serum HDL was an independent risk factor for renal disease progression, although the study of the relation between hyperlipidemia and risk factor for CKD was not sufficient to determine a conclusion (15). In the Atherosclerosis Risk in Communities Study, the high serum triglycerides and low HDL cholesterol were associated with an incident rise in the serum creatinine. Additionally, the relative risks obtained by comparing the highest with the lowest quartile of HDL and triglycerides were all significantly different from 1.0. The risk of a rise in the se- 
rum creatinine for the highest quartile of triglycerides was 1.65 times that for the lowest quartile. Persons in the highest quartiles of HDL cholesterol had a relative risk of 0.47 (16). In a Japanese epidemiological study, Iseki et al reported that the adjusted hazard ratio for dyslipidemia was not a significant predictor of the development of ESRD in CKD patients (17).

Hypertension was also found to be a significant risk factor in this study. This result is definitely in accordance with many previous reports. In the MDRD study (18), in the patients in the lower blood pressure group (mean blood pressure, $92 \mathrm{mmHg}$ ) the interval to ESRD was longer as compared with that in the usual blood pressure group (mean blood pressure, $107 \mathrm{mmHg}$ ).

Age did not influence the progression of renal dysfunction. It was reported that young age was a risk factor for the progression of IgA nephropathy $(6,19)$. However, several conflicting reports have also been published $(20,21)$. One of limitations is the setting of age at 60 . Gender was found to have no influence in this study. In a previous report, men with stage 4 or $5 \mathrm{CKD}$ were at greater risk of progression to ESRD (8). Morita et al also reported, based on the results of a multivariate analysis, that gender was not a risk factor in CKD patients (22).

High BMI and metabolic syndrome were not found to be significant risk factors in this study; however, high BMI and metabolic syndrome did tend to accelerate the progression of renal dysfunction (23). BMI in the highest quartile (more than 30) was a significant risk factor. Iseki et al reported that BMI was associated with an increased risk of development of ESRD in men in the general population (24). The association of obesity with the rate of progression of CKD is assumed to be related to factors such as glomerular hypertension, hyperlipidemia, hyperleptinemia, resistin, insulin re- sistance, hyperinsulinemia, TGF $\beta 1$, increased sympathetic activity, and an activated rennin-angiotensin system. In this study, metabolic syndrome was not found to be a significant risk factor, however, a relation between metabolic syndrome and chronic kidney disease has been reported from epidemiological studies. Tanaka et al demonstrated that the prevalence of CKD increases linearly with the number of components of the metabolic syndrome (25). Ninomiya et al reported, from a prospective cohort study, that the cumulative incidence of CKD was significantly greater in subjects with metabolic syndrome than in those without in the general population (26).

One of the limitations is the low number of study population. To analyze risk factors for progression of CKD a larger population for statistical power is necessary. Another limitation of this study is the method of calculation of eGFR slope lead by only two points of eGFR in accuracy. Therefore, for the next prospective study it is planned to use the regression line from several eGFR values and the doubling time of serum creatinine. The interventional study for CKD should be designed to research therapeutic effects.

In summary, we investigated the risk factors for disease progression in patients with early-stage CKD in a retrospective cohort at a single center. Proteinuria, smoking habit, hypertension and low serum HDL were clearly related to accelerated progression of early-stage CKD to ESRD. Aggressive treatment of these risk factors is therefore essential in patients with early-stage CKD.

\section{Acknowledgement}

This work was supported by a grant from the Japan Research Promotion Society for Cardiovascular Diseases. We especially wish to thank Ai Munekawa, Mayuko Tsuboi and Atsuko Teraoka for their technical assistance.

\section{References}

1. Imai E, Horio M, Iseki K, et al. Prevalence of chronic kidney disease (CKD) in the Japanese general population predicted by the MDRD equation modified by a Japanese coefficient. Clin Exp Nephrol 11: 156-163, 2007.

2. Stengel B, Billon S, Van Dijk PC, et al. Trends in the incidence of renal replacement therapy for end-stage renal disease in Europe, 1990-1999. Nephrol Dial Transplant 18: 1824-1833, 2003.

3. Go AS, Chertow GM, Fan D, McCulloch CE, Hsu CY. Chronic kidney disease and the risks of death, cardiovascular events, and hospitalization. N Engl J Med 351: 1296-1305, 2004.

4. Sarnak MJ, Levey AS, Schoolwerth AC, et al. Kidney disease as a risk factor for development of cardiovascular disease: a statement from the American Heart Association Councils on Kidney in Cardiovascular Disease, High Blood Pressure Research, Clinical Cardiology, and Epidemiology and Prevention. Circulation 108: 21542169, 2003.

5. Imai E, Horio M, Nitta K, et al. Modification of the Modification of Diet in Renal Disease (MDRD) Study equation for Japan. Am J Kidney Dis 50: 927-937, 2007.

6. Vikse BE, Bostad L, Aasarød K, et al. Prognostic factors in mesangioproliferative glomerulonephritis. Nephrol Dial Transplant 17: 1603-1613, 2002.
7. Executive Summary of The Third Report of The National Cholesterol Education Program (NCEP) Expert Panel on Detection, Evaluation, And Treatment of High Blood Cholesterol In Adults (Adult Treatment Panel III). JAMA 285: 2486-2497, 2001.

8. Omae K, Ogawa T, Nitta K. Risk factors for deterioration of renal function in chronic glomerulonephritis: Multivariate analysis of risk factors at various disease stage in patients with chronic kidney disease. Junkankika 62: 195-202, 2007 (in Japanese).

9. Ruggenenti P, Perna A, Mosconi L, et al. Urinary protein excretion rate is the best independent predictor of ESRF in non-diabetic proteinuric chronic nephropathies. "Gruppo Italiano di Studi Epidemiologici in Nefrologia" (GISEN). Kidney Int 53: 1209-1216, 1998.

10. Yamagata K, Iseki K, Nitta K, et al. Chronic kidney disease perspectives in Japan and the importance of urinalysis screening. Clin Exp Nephrol 12: 1-8, 2008.

11. Keller CK, Bergis KH, Fliser D, Ritz E. Renal findings in patients with short-term type 2 diabetes. J Am Soc Nephrol 7: 2627-2635, 1996.

12. Orth SR, Stockmann A, Conradt C, et al. Smoking as a risk factor for end-stage renal failure in men with primary renal disease. Kidney Int 54: 926-931, 1998. 
13. Orth SR, Ritz E. The renal risks of smoking: an update. Curr Opin Nephrol Hypertens 11: 483-488, 2002.

14. Orth SR, Hallan SI. Smoking: a risk factor for progression of chronic kidney disease and for cardiovascular morbidity and mortality in renal patients--absence of evidence or evidence of absence? Clin J Am Soc Nephrol 3: 226-236, 2008.

15. Hunsicker LG, Adler S, Caggiula A, et al. Predictors of the progression of renal disease in the Modification of Diet in Renal Disease Study. Kidney Int 51: 1908-1919, 1997.

16. Muntner P, Coresh J, Smith JC, et al. Plasma lipids and risk of developing renal dysfunction: the atherosclerosis risk in communities study. Kidney Int 58: 293-301, 2000.

17. Iseki K, Tozawa $M$, Ikemiya $Y$, et al. Relationship between dyslipidemia and the risk of developing end-stage renal disease in a screened cohort. Clin Exp Nephrol 9: 46-52, 2005.

18. Klahr S, Levey AS, Beck GJ, et al. The effects of dietary protein restriction and blood-pressure control on the progression of chronic renal disease. Modification of Diet in Renal Disease Study Group. N Engl J Med 330: 877-884, 1994.

19. Fofi C, Pecci G, Galliani M, et al. IgA nephropathy: multivariate statistical analysis aimed at predicting outcome. J Nephrol 14:
280-285, 2001.

20. Coppo R, D'Amico G. Factors predicting progression of $\operatorname{IgA}$ nephropathies. J Nephrol 18: 503-512, 2005.

21. Komatsu H, Fujimoto $S$, Hara $S$, et al. Multivariate analysis of prognostic factors and effect of treatment in patients with IgA nephropathy. Ren Fail 27: 45-52, 2005.

22. Morita S, Fukuhara S, Akizawa T, et al. Prognostic factors for a composite end-point of renal outcomes in patients with chronic kidney disease. Ther Apher Dial 10: 72-77, 2006.

23. Praga M. Obesity--a neglected culprit in renal disease. Nephrol Dial Transplant 17: 1157-1159, 2002.

24. Iseki $\mathrm{K}$, Ikemiya $\mathrm{Y}$, Kinjo $\mathrm{K}$, et al. Body mass index and the risk of development of end-stage renal disease in a screened cohort. Kidney Int 65: 1870-1876, 2004.

25. Tanaka H, Shiohira Y, Uezu Y, et al. Metabolic syndrome and chronic kidney disease in Okinawa, Japan. Kidney Int 69: 369374, 2006.

26. Ninomiya T, Kiyohara $Y$, Kubo M, et al. Metabolic syndrome and CKD in a general Japanese population: the Hisayama Study. Am J Kidney Dis 48: 383-391, 2006.

(C) 2008 The Japanese Society of Internal Medicine http://www.naika.or.jp/imindex.html 